\title{
CHARTING THE PRESENT OF TEACHING THE PAST: PROPAGANDA AND 1776 IN THE HISTORY CLASSROOM
}

Hunter Watts

Normal Community High School

Normal, Illinois
Teaching History 46(2)

DOI: $10.33043 / \mathrm{TH} .46 .2 .45-48$

(C) 2021 Watts.

Distributed with CC BY-NC-ND 4.0 License.

Published just twelve days after the attack on the United States Capitol in January 2021 and taken down just two days later on the day of President Biden's inauguration, the Trump Administration's 1776 Report was a mere flash in the pan in the battle for America's history classrooms. Despite being just a flash, the report is indicative of larger trends in America's contemporary history and culture wars. Written as a response to The New York Times' 1619 Project, works published by polarizing historians like Howard Zinn, and the perceived growth of critical race theory in classrooms, the goal of the 1776 Report was to provide a renewal of "patriotic education" and a correction to the "radicalized view of American history." The report lacks almost any evidence of historical thought and rigor, perhaps because not a single United States historian was consulted in its creation. There is a distinct difference between materials that contribute to quality history education and propaganda, the latter of which more properly describes the 1776 Report.

While there are many frameworks that could be used to analyze the report's viability for history curriculum, Thomas Andrews and Flannery Burke's "Five C's of Historical Thinking" is particularly well suited for the task. ${ }^{2}$ Published in 2007 in the American Historical Association's magazine, Perspectives on History, Andrews and Burke's Five C's of Historical Thinking include context, causality, contingency, change over time, and complexity. These historians argue that the Five C's "stand at the heart of the questions historians seek to answer, the arguments we make, and the debates in which we engage." ${ }^{3}$ Since its publication, the framework has been widely used as a tool to teach the myriad of complicated skills required for a proper study of history. The habits of mind articulated in the Five C's are fundamental to historical thinking, and therefore, reports or other secondary sources intended to be used as part of the history curriculum should be evaluated through the lens of the Five C's. Reports that do not hold up to the Five C's are ahistorical at best or propaganda at worst.

\section{Context}

Perhaps the most obvious of the Five C's, context is a good starting point for scrutinizing secondary sources. It is vitally important that historians analyze past events and sources in the context of the times and situations in which they occurred or were created. The 1776 Report is only forty pages long, half of which is a series of appendices attempting to reiterate universal American values. This leaves a measly twenty pages for outlining a story of the Founding, challenges to American principles, and charting a path for "National Renewal." Because of the small amount of space given to such a lengthy task, it could almost be excused to lack certain context, except the stated goal of the report is to, "enable a rising generation to understand the history and principles of the founding..." Conceivably, a goal as lofty as this cannot be completed in just twenty pages. The account of the Founding that the report offers is monolithic and leaves no room for the nuanced arguments that took place among the Founders as they created the system of government articulated by the Constitution.

In addition to a monolithic approach, random pictures of historical paintings and figures are inserted in the report without context or sometimes even relevance to what is written on the page. Quotes of various individuals are inserted just as randomly. In one baffling instance, a quote from Frederick Douglass is used to

\footnotetext{
${ }^{1}$ The President's Advisory 1776 Commission, “The 1776 Report,” January 2021.

${ }^{2}$ Thomas Andrews and Flannery Burke, "What Does It Mean to Think Historically?" Perspectives on History 45, no. 1 (January 2007), https://www.historians.org/publications-and-directories/perspectives-on-history/january-2007/what-does-it-mean-to-thinkhistorically

${ }^{3}$ Ibid.
} 
show his supposed reverence and endorsement of the Founding principles. ${ }^{4}$ The context of this quote, however, is important given that it is from Douglass's 1852 speech, "What to the Slave is the Fourth of July?" The quoted excerpt is obviously cherry-picked, and the lack of context is either horribly ignorant or, worse, intentionally misleading. Later in the same speech, Douglass explained, "The rich inheritance of justice...is shared by you, not by me...The Fourth [of] July is yours, not mine." Douglass gave this scathing speech about the Fourth of July in 1852, but readers can be forgiven for not knowing Douglass' argument when the context of the quote is left out. The missing context is rampant in the report and the Douglass quote is merely one example. In paragraph after paragraph, quotes are selected without regard to their source, statements and claims are made without proper support, and grand conclusions are drawn without consideration given to the past. Given the distinct lack of context throughout the 1776 Report, it remains more of a polemic argument as opposed to a useful historical source.

\section{Causality}

Causality is the next of the Five C's. Historians often look to answer why and when particular events unfolded the way they did. Rather than attribute events to single causes, quality historical study aims to explain the past in terms of multiple causes. This is not the case in the 1776 Report. Rather than attribute multiple causes to historical events, the report aligns the creation of the Constitution with a single cause-the existence of universal American values. For the writers of the report, the movement of history is simple; either people live up to American ideals or they do not. When people fail to live up to the ideals, social unrest takes place. Rather than offer a nuanced explanation of the founding in terms of a web of many forces coming together at various times, the report offers a teleological view of history, essentially claiming that because the principles of the Declaration are "universal and eternal," the creation of the United States was inevitable.

Throughout the entire document, events are detailed in terms of what happened, but rarely if ever, is the question of why things happened the way they did explored. This approach leaves an unsatisfying version of the American Founding. Because of the report's philosophical approach to the Founding, readers are left with a mass of unanswered questions. Why are the stated American principles considered to be natural? Why have Americans been divided on these American principles throughout the past? How is John Calhoun the founder of identity politics? For the writers of the report these answers are simple, and all have a single cause-because they are ideals the Founders built on, because some people did not live up to said ideals, and because Calhoun did not live up to the Founding principles.

\section{Contingency}

To the historical thinker, contingency is about considering the fact that historical events were not destined to occur the way they did. In other words, historical events are contingent upon a series of previous events leading up to them. Contingency ensures that students of history do not walk away with a teleological view of events. The 1776 Report plainly fails in this aspect of historical thinking. To understand that the report was written as a contemporary response to the heightened period of polarization, one need not look any further than the series of appendices at the end. The document's four appendices are perhaps the most enlightening. The first is the Declaration of Independence. The second is a series of comments on America's principles and Founders which reads more as religious activism than as a historical reflection. The third covers identity politics, including a reduction of John Calhoun as the founder of identity politics and a disingenuous analysis of critical race theory. The final appendix is an attack on current history education and a call for a restoration of patriotic history. If this document were to be of historical significance, nearly half of it would not be dedicated to addressing

\footnotetext{
${ }^{4}$ The President's Advisory 1776 Commission, “The 1776 Report,” January 2021.

${ }^{5}$ Frederick Douglass, "What to the Slave is the Fourth of July?" July 5, 1852, available at https://teachingamericanhistory.org/ document/what-to-the-slave-is-the-fourth-of-july/
} 
contemporary political discourse. In this way, the 1776 Report is written from the present backwards. It is teleological in its analysis of history and fails to understand the contingency of historical events that brought about the present. Rather, it forces contemporary discourse upon the past, manipulating it for political gain.

\section{Change Over Time}

Andrews and Burke claim that change over time is the easiest of the Five C's to grasp. This concept is about studying growth, decline, and continuity. Studying these trends offers grand insight into the interpreted course of historical events. Despite change over time being the easiest of the Five C's to grasp, the writers of the 1776 Report write history as being stagnant. This approach is evident in the overwhelming commitment to national ideals that the report holds. Rather than portray the Founding as an evolution of events through the various perspectives of the different Founders, the writers of the report paint the Founding as a single-track monolithic event. Readers of the report could be excused for thinking that the creation of the Constitution was a clean process devoid of all conflict or vying interests. Further, the report suggests that change at all is threatening to the national ideals it describes. In a section on progressivism, the writers argue that changes in how citizens view the Constitution are dangerous to the foundation of the country. The idea that the Constitution might be a "living document" applicable to evolving times is pinned as heresy, despite it being the core argument of many of the Founders and arguably displaying far more impressive foresight. The Constitution is not a stagnant document. This is evident in the evolution of amendments and how courts have interpreted laws over time. The idea that the document is stagnant flies in the face of Thomas Jefferson's view of constitutional government, that the earth belongs to the usufruct of the living and that therefore the entire Constitution should be rewritten every generation. This disregard for Jefferson's perspective is ironic given the reverence for him displayed in earlier sections of the report. Rather than track this far more impressive change over time, the 1776 Report paints a plain and stagnant picture of United States history, one where change is viewed as inherently backwards.

\section{Complexity}

The last of the Five C's, and the one that the 1776 Report perhaps falters with most, is complexity. History is messy. It is a complicated ongoing argument about the past that requires nuance to navigate properly. Yet the report suggests that history is simple and straightforward, and anyone who tries to argue otherwise violates American principles. The lack of complexity in the report is most evident in the discussion of challenges to America's principles. In this section, slavery, progressivism, communism, fascism, and identity politics are equivocated as threats to American democracy. Rather than confront the uniqueness of American chattel slavery or the irony of the Founders holding slaves, the 1776 Report chalks slavery up as an unfortunate circumstance of the time with no lesson to be learned. Discussions of progressivism, fascism, and communism all lack complexity, and an in-depth analysis of any topic (for example, the influence of the Communist Party on labor and civil rights activism) is completely ignored. The section on identity politics is the most telling. In one paragraph, the report praises the Civil Rights Movement (and specifically Martin Luther King Jr., notably a progressive-socialist) for commitments to American ideals. In the next paragraph, the militancy and radicalization of the movement in the late 1960s is condemned, ignoring the complexity of why the movement trended in that direction. Even just a few sentences about the connections to Vietnam, connections to economic and class problems, or the failure of legislation to uphold American principles would shed a vastly different light on the report's telling of these seemingly simple events.

\section{Conclusion}

In all, the 1776 Report fails at all five pillars of this framework, leaving readers to determine whether the report is merely ahistorical, or whether it is misleading propaganda. Given the stated goals of the report and the myriad of misleading information found within its short telling of the United States founding, the 1776 Report is better described as propaganda. It is no wonder that historians have almost universally denounced the 1776 
Report as a legitimate piece of historical writing. Sam Wineburg charts out the act of historical thinking in his work, Historical Thinking and Other Unnatural Acts: Charting the Future of Teaching the Past. ${ }^{6}$ In this work, Wineburg distinguishes what most people think of history-a body of stagnant facts-from how historians view history - as a method of knowing information in order to develop understanding. History is an ongoing argument about the past fueled by rigorous source examination and interpretation. Perhaps Michael Kazin put it best: "[T]he 1776 Report reveals profound ignorance about what professional historians of the United States actually think and do." It is clear that the writers of the 1776 Report do not understand historical thinking.

Historical arguments are always reflective of the time in which they were written. In this case, the 1776 Report was created during a period of heightened tension in the culture wars specifically focused on the teaching of history. Reducing the study of history down to pinpointing a single year is inherently reductionist. However, the selected year can illuminate the perspective of the writers. In this case, the selection of 1776 and the call for restoring patriotic education is a clear response to contemporary events. Students of history should learn to wrestle with the past in all its facets. Ignoring historical wrongs does little to improve society. It is natural for modern politics to influence school curriculum, just as it is natural for modern politics to influence the study of history. The danger in this influence, however, comes when it overshadows quality and a meaningful study of history. When history is manipulated to serve the politics of the day, it is no longer history. It becomes propaganda. The study of history is not inherently a patriotic act, nor should it be. Honest study of history helps societies to learn, grow, and develop into something more than the sum of their parts.

\footnotetext{
${ }^{6}$ Sam Wineburg, Historical Thinking and Other Unnatural Acts: Charting the Future of Teaching the Past (Philadelphia: Temple University Press, 2001).

${ }^{7}$ Michael Kazin, "The 1776 Follies," New York Times, Feb. 1, 2021, https://www.nytimes.com/2021/02/01/opinion/trump-1776commission-report.html
} 